\title{
50-“el-Tantûriyye” romanındaki kültürel ögelerin çevirisi üzerine bir inceleme
}

\author{
Ahmed ALDYAB ${ }^{1}$ \\ Tuğçe KETTANEH ${ }^{2}$
}

APA: Aldyab, A.; Kettaneh, T. (2021). "el-Tantûriyye" romanındaki kültürel ögelerin çevirisi üzerine bir inceleme. RumeliDE Dil ve Edebiyat Araştırmalar Dergisi, (25), 831-843. DOI: 10.2900o/rumelide.1037418.

\section{$\ddot{O} \mathbf{z}$}

Mısırlı yazar Radvâ Âşûr, Arap edebiyatında tarihi romanın en ünlü temsilcilerindendir. Türkçede yayımlanan ilk eseri olan Tantûralı Kadın romanında mecbur bırakıldıkları sürgünün zorluklarıyla dolu yaşam öyküsü bir kadının gözünden anlatılırken, diğer taraftan da tarihe tanıklık söz konusudur. Filistin'de yaşananları 1948 yılı öncesinden başlayarak 200o'li yıllara kadar anlatan edebi dille yazılmış tarihi bir romandır. Sürgün, savaş, ölüm, sevda, hayat gibi kavramları barındıran eser, kültürel ögeler bakımından zengindir. Kültürel ögelerin çevirisi, erek dile aktarımı, kaynak dil kültürünün korunumu çeviri bilim alanında önemli bir yer tutar. Bu çalışmada, İngiliz çeviri bilimci Peter Newmark' in “A Textbook of Translation” kitabındaki kültürel ögelerin sınıflandırılması doğrultusunda Radvâ Âşûr'un el-Tantûriyye romanındaki kültürel ögeler, kullanılan çeviri stratejileriyle tespit edilerek, çeviri analizleri çeviri bilim araştırmacısı Venuti'nin yerlileştirme (domestication) ve yabancılaştırma (foreignization) stratejilerine göre yapılmıştır. Yerlileştirme, erek kültürde anlaşılabilirlige, kabul görmeye yönelik bir stratejidir ve kültürlerarası fark önemli bir unsur değildir. Çeviri sürecinde kültürel ögeler değiştirilebilir, eklenebilir, çıkarılabilir. Yabancılaştırma stratejisinde ise; kaynak metindeki yabancı unsurlar korunur, kültürel farklılıklar erek metne yansıtılarak erek okur, yeni bir kültürle tanıştırılır. Bu stratejide; çeviri sürecinde dipnot kullanma, aktarım, açımlama yapma gibi uygulamalara başvurulabilir. Bu doğrultuda, erek dile aktarılan kültürel ögelerin çevirmen tarafından hangi stratejilerle aktarıldığı hakkında bilgiler verilmiştir. Ayrıca bu stratejilerin önemi, çevirilerin kaynak dil ve kültürünü ne ölçüde yansıttığı örneklerle birlikte açıklanmıştır.

Anahtar kelimeler: Radvâ Âşûr, Tantûralı Kadın, kültürel ögeler, Newmark, çeviri stratejileri

\section{An analysis on the translation of cultur elements in Radva Asur's "The Woman From Tantura"}

\begin{abstract}
Egyptian writer Radvâ Âşûr is one of the most famous representatives of historical novel in Arabic literature. In her novel Tanturalı Kadın, her first work published in Turkish, a life story full of the hardships of the exile they were forced to is told through the eyes of a woman, on the other hand, there is a witness to history. It is a historical novel written in a literary language, describing the events in Palestine from before 1948 to the 2000s. The work, which contains concepts such as exile, war,

Dr. Öğr. Üyesi, Ankara Yıldırım Beyazıt Üniversitesi, İnsan ve Toplum Bilimleri Fakültesi, Doğu Dilleri ve Edebiyatları Bölümü, Arapça Mütercim Tercümanlı ABD (Ankara, Türkiye), ahmad.adyab@gmail.com, ORCID ID: 000o-00029497-9197 [Araştırma makalesi, Makale kayit tarihi: 11.11.2021-kabul tarihi: 20.12.2021; DOI: 10.29000/rumelide.1037418]

2 YL Öğrencisi, Ankara Yıldırım Beyazıt Üniversitesi, Sosyal Bilimler Enstitüsü, Arap Dili ve Edebiyatı (Ankara, Türkiye), tgcyzck@gmail.com, ORCID ID: oooo-0002-4460-4370
\end{abstract}


death, love and life, is rich in cultural elements. The translation of cultural elements, their transfer to the target language, the preservation of the source language culture have an important place in the field of translation studies. In this study, in line with the classification of cultural elements in the British translation scientist Peter Newmark's A Textbook of Translation, the cultural elements in Radvâ Âşûr's al-Tantûriyye novel were determined by the translation strategies used, and the translation analysis was applied to the translation studies researcher Venuti's domestication and foreignization strategies. made accordingly. Indigenization is a strategy for intelligibility and acceptance in the target culture and there is no distinction between cultures. Cultural elements can be changed, added or removed during the translation process. In the alienation strategy, the foreign elements in the source text are preserved, cultural differences are reflected in the target text, and the target reader is introduced to a new culture. In this strategy, practices such as using footnotes, transferring, and paraphrasing can be applied during the translation process. In this direction, the strategies in which the cultural elements transferred to the target language are transferred by the translator, the importance of these strategies, and the extent to which the translations reflect the source language and culture are explained with examples.

Keywords: Radva Asur, woman with Tantura, cultural elements, Newmark, translation strategies

\section{Giriş}

Diller ve kültürler arası anlaşılırlığı sağlamak üzere köprü görevi gören ve bir iletişim aracı olan çeviri, sadece dilbilimsel düzeyde kalmayı, aktarıldığı toplumun gelenek, göreneklerini ve kültürünü de aktaran bir etkinliktir. Herhangi bir ileti çevrilirken yalnızca başka dile değil aynı zamanda başka kültüre de aktarılır. Zira her dilin kendi kültürüne has semboller dizgisi vardır ve her kültür, kavramsal olgularını ifadeye dönüştürürken deneyimlerini, en iyi ifade edebildiği kendi diliyle açıklar (Çamdereli,1995: 48). Geçmişten günümüze önemini artırarak devam eden çeviri hareketleri, pek çok alanda kullanılmasının yanı sıra edebiyat alanında da oldukça önemlidir. Herhangi bir eser farklı çevirmenlerce tercüme edilerek yayımlanabilmektedir. Buradaki en önemli husus, kaynak kültürün ve hedef metnin erek dile aktarıldığında okur tarafından anlaşılır olmasıdır. Aktarılan dile hakimiyetin yanı sıra, kaynak dil ve kültürü de çok iyi bilmek ve bunu en anlaşılır şekliyle erek dile aktarmak başarılı bir çevirinin olmazsa olmazıdır. Çevirmenin kaynak kültüre ait gelenek- görenekleri, coğrafyayı, yaşam biçimini iyi bilmemesi durumunda erek dilde anlam ve çeviri kayıpları, okuyucu için tercüme edilen eseri veya metni anlamasını zorlaştıracaktır.

Çeviride, mütercim toplumlar arasında anahtar vazifesi görmektedir. Çünkü mütercim farklı dillerde telif edilmiş bilgileri tercüme ederek insanlığa kazandırır. Mütercimin başarılı çeviriler yapabilmesi için farklı kültürler hakkında bilgi sahibi olması, alanında kendini yetiştirmesi ve bilimsel terimleri iyi bilmesi gerekir. Ayrıca, mütercimin kaynak ve hedef dile hâkim olması çevirinin anlaşılır olması açısından önemli bir husustur (Bölükbaşı, 2021:728).

Çeviri, eskiden olduğu gibi günümüzde de önemini koruyan önemli bir faaliyettir. Çeviri sadece bir metni istenilen dile aktarmaktan ibaret değildir. Aynı zamanda toplumlar arasında bilgi aktarımını gerçekleştiren önemli bir etkinliktir. Çeviriler, kadim kültürlere ait önemli kaynak eserlerde yer alan bilgilerin dünyanın farklı dillerine aktarılmasında önemli rol oynamış ve bu sayede medeniyetlerin bilim, sanat ve tıp alanlarında ilerleme kaydetmelerine büyük katkı sağlamışlardır (Bölükbaşı, 2021:722). 
Bu çalışmada, 1948'de başlayan zorunlu sürgünle karşı karşıya kalan Filistinlerin yaşam öyküsünü okuyucuya sunan el- Tantûriyye ile erek metni karşılaştırmalı olarak kültürel ögeler bağlamında ele alınmış ve kullanılan çeviri stratejilerine yönelik çıkarımlara varılmıştır.

\section{Kültürün tanımı ve çevirinin kültür etkileşimi üzerindeki etkisi}

Türkçe sözlükte kültür; "Tarihsel, toplumsal gelişme süreci içinde yaratılan bütün maddi ve manevi değerler ile bunları yaratmada, sonraki nesillere iletmede kullanılan, insanın doğal ve toplumsal çevresine egemenliğinin ölçüsünün gösteren araçların bütünü” olarak ifade edilmiştir (Akalın, vd., 2011: 1558). Latince "colere" kökünden gelen ve etimolojik olarak sürmek, ekip biçmek, tarımda gelişmek gibi anlamlara gelen kültür sözcüğü "cultura" den türemiş ve Türkçede de ekin manasında kullanılmıştır (Eagleton, 2000: 10).

Newmark, "A Textbook of Translation (1988) adlı eserinde kültürü "yaşam tarzı, bu yaşam tarzının belirli bir dili ifade aracı olarak kullanan toplumdaki tezahürü” olarak ifade etmiştir (s.94). Kültürün tanımları şunu göstermektedir; dil ile kültür öylesine birbirine bağlıdır ki bu iki kavramı birbirinden ayrı düşünmek mümkün değildir. Kültür dile kaynaklık ederken, dil de kültürün aktarılmasındaki en önemli araçtır. Dil kültürün taşıyıcısıyken; kültür de dile kaynaklık eden önemli araçtır (Göçer, 2012: 55).

Dil ve kültür ait olduğu millet tarafından yüzyllarca yoğrulur. Bir nehir gibi, geçtiği topraklardan bazı unsurları alarak akar. Bu bakımdan dile, ait olduğu milletin çağlar boyunca yaşamış olduğu tarihinin özeti olarak baktığımızda mâna kazanacaktır (Kaplan, 2020: 155). Çeviri, yalnızca bir dilden diğerine aktarımla kalmayıp aynı zamanda bir kültürden diğer kültüre de aktarımda bulunmaktır. Öyle ki çeviride kültürel farklılıkların sebep olduğu çeviri sorunları, dil bilgisel kaynaklı çeviri sorunlarından çok daha büyüktür (Suçin, 2013:134-135). Bundan dolayı herhangi bir dile ait kültürel ögeler başka bir dile aktarıldığında, diller ve kültürler arası çeşitlilik ve farklılıklardan dolayı okuyucu bakımından çeşitli zorluklara ve istenilen anlamın okuyucuya ulaşamamasına, çeviride anlamsal boşluklara yol açabilmektedir.

Çeviriler, farklı milletlere ait tıp, astronomi, matematik ve edebiyat alanında telif edilmiş önemli kaynak eserleri birbirleriyle paylaşmalarına büyük katkı sağlamıştır. Ayrıca çeviriler neticesinde kültürler arası iletişim artmış ve bu etkileşim toplumların birçok alanda gelişmesine katkı sağlamıştır. Hintçe telif edilmiş olan 'Kelile ve Dimne' adlı eser önce Farsçaya daha sonra İbnu'l-Mukaffa'(ö.759) tarafından Farsçadan Arapçaya çevrilmiştir. Bu eserde Hint ve Fars kültürlerine ait birtakım öğeler Arap kültürüne aktarılmıştır. 'Kelile ve Dimne' kelimeleri Arapça veya Farsçada bulunmamaktadırlar çünkü bu kelimeler Hintçedir. $\mathrm{Bu}$ durum çevirinin kültür aktarımında önemli bir role sahip olduğunu göstermektedir (Bölükbaşı, 2021: 67). Batı dünyasında Rönesans hareketlerini ve Arap-İslam dünyasında bilimsel gelişmeleri başlatan en önemli etken çeviri faaliyetleridir. Bu etkinlikler kadim milletlere ait eserlerin Arapçaya ve Batı dillerine çevrilmesinde kilit rol oynamış ve bu sayede Doğu ve Batı dünyası birçok alanda ilerleme kaydetmiştir. Çeviriler sayesinde toplumlar arası kültür aktarımı meydana gelmiş ve bu aktarımlar toplumların birbirlerini tanımalarına olanak sağlamıştır (Bölükbaşı, 2021:72). 


\section{Radvâ Âşûr' ve el- Tantûriyye}

1946'da Mısır'da dünyaya gelen Radvâ Âşûr, Kahire Üniversitesinde İngiliz Dili ve Edebiyatı bölümünden mezun olduktan sonra mastırına da burada Karşılaştırmalı Edebiyat alanında devam etti. ABD' de tamamladığı doktorası Afro-Amerikan edebiyatı üzerineydi. Gassan Kenafani’ nin eserlerini incelediği ve bir edebiyat eleştirisi olan "Başka bir Kampa Uzanan Yol" adlı ilk eseri 1977'de yayımlandı. Çok sayıda roman, hikâye, gezi yazısı, edebiyat eleştirisi, akademik eser ortaya koyan Radvâ Âşûr; 1994 tarihinde yayınladığı "Granada Üçlemesı" romanı Kahire Uluslararası Kitap Fuarı'nda En İyi Kitap Ödülü’nü kazandı. Kitap, en popüler Mısır romanlarından biri oldu.1999- 2012 ylları arasında dört roman yayınladı, bunların içerisinde en önemlileri "Tantûrah Kadın"'dı. Romanda Filistin' in Hayfa şehrinin güneyinde bulunan Tantûra Köyü'nde 1948'de siyonist çetelerce gerçekleştirilen katliam, zorunlu sürgün, mülteci kamplarında ve mülteci olarak yaşamanın tüm zorlukları, işgal ve sürgünün tarihi Tantûralı Rukayye'nin gözünden anlatılmaktadır. Radvâ Âşûr, Filistin halkının mücadele ve direnişine her zaman destek olmuş bir isimdir ve Filistinlilerin topraklarına geri dönebilmesi için her alanda elinden geleni yapmıştır. 2014 ylında Kahire'de hayatını kaybetmiştir.

\section{Kültürel ögeler}

Peter Newmark, 1988 yılında yazmış olduğu, dil, kültür ve çeviri arasındaki ilişkiye değinen “ $A$ Textbook of Translation" adlı kitabında kültürel ögeleri beş ana kategoride sınıflandırmıştır:

1. Çevresel unsurlar: Jeolojik ve coğrafi çevre

2. Maddi kültür: yiyecek-içecekler, giyim kuşam, konaklama (evler ve şehirler), ulaşım araçları

3. Sosyal yaşam: çalışma hayatı ve özel hayat

4. Kurumlar, gelenek ve görenekler, etkinlikler, işlemler, kavramlar: siyasi ve idari konular, dini konular, sanatsal konular, deyimler ve kalıp ifadeler

5. Alışkanlıklar ve davranışlar: El kol hareketleri, jest ve mimikler, kişisel alışkanlıklar

Newmark daha sonra kitabında yaptığı bu sınıflandırmayı gözden geçirerek 2010 yılında "Translation and Culture" (Çeviri ve Kültür) adıyla yayınladığı makalede 6 kategori olacak şekilde güncellemiştir. Buna göre sinıflandırma şu şekildedir:

1. Çevre: Jeolojik ve coğrafi çevre

2. Kamu hayatı: Politika, hukuk ve yönetimi

3. Sosyal yaşam: Ekonomi, meslekler, toplumsal refah, sağlı ve eğitim

4. Kişisel yaşam: Yiyecekler, kılık kıyafet ve ev eşyaları

5. Gelenek-görenekler ve sosyal etkinlikler: Yavaş alkışlama ve masaya vurarak alkışlama gibi gelenekler, kriket ve futbol gibi sosyal etkinlikler ve bunlara bağlı tüm ulusal deyimler

6. Kişisel merak ve tutkular: Din, müzik, şiir ve bunlara bağlı çeşitli toplumsal kuruluşlar, sanatsal kuruluşlar (Newmark,2010, s.94) 
Newmark, çevirinin temel sorununun kaynak dil odaklı mı yoksa erek dil odaklı mı yapılacağını belirlemek olduğunu ifade ederek kitabının "Çeviri Metotları" bölümünde ünlü V diyagramından bahsetmektedir (Newmark, 1988, s.45).

KAYNAK DİL ODAKLI

Sözcüğü Sözcüğüne

Bağımlı Çeviri

Sadık Çeviri

Anlamsal Çeviri

\section{EREK DİL ODAKLI}

Uyarlama

Serbest Çeviri

Deyimsel Çeviri

İletişimsel Çeviri

Newmark, çevirinin temel sorunun kaynak metinde geçen kültürel ögelerin erek metinde bir karşılığının olmamasından kaynaklandığını belirtmektedir. Bu durumu önlemek için kaynak metnin iyi bir şekilde anlaşılarak çözümlenmesine önem vermektedir. Bu tespitler doğrultusunda çeviri yöntemlerini açiklamaktadır:

1. Sözcüğü sözcüğüne çeviri (Word-for-word Translation): Kelimelerin en yaygın anlamlarıyla çevrilmesidir. Kültür kelimeleri olduğu gibi aktarılır.

2. Birebir çeviri (Literal Translation): Kelimelerin erek dile birer birer çevrilmesidir. Genellikle teknik çevirilerde ve aynı veya benzer kültür çevirisinde kullanılır.

3. Bağımlı / sadık çeviri (Faithful Translation): Bu yöntemde çevirmen metinde hedeflenen anlama sadık kalır.

4. Anlamsal çeviri (Semantic Translation): Bu yöntemde çevirmene esneklik imkânı verilerek, üslubuna estetik değer katması sağlanır.

5. Uyarlama (Adaptation): Kaynak metindeki bir ifadenin hedef dilde karşılığının olmadığı ya da bilinmediği durumlarda kullanılır. Genellikle sanat eserleri, edebi eserler, film ve kitap çevirilerinde başvurulan bu yöntem serbest çeviri tekniklerinde en fazla tercih edilendir.

6. Serbest çeviri (Free Translation): Kaynak metindeki biçim, üslup ve içeriğe bağlı kalmadan, gerçek çeviri olarak kabul edilmeyen bir yöntemdir.

7. Deyimsel çeviri (Idiomatic Translation): Kaynak dilde deyimsiz ifade edilen bir ifadenin erek dilde deyimlerle ifade edilmesiyle yapılan çeviri, doğallığa en yakın yöntemdir.

8. İletişimsel çeviri (Communicative Translation): Kaynak metnin dil ve içerik açısından anlaşılır bir üslupla okuyucuya aktarılmasıdır. Metni basite indirgeyerek, ileti' ye odaklanır ve genellikle akademik amaçlıdır (Newmark, 2010: 45-48).

Newmark (1988) "Çeviri yöntemleri bütün metni ilgilendirirken çeviri süreçleri cümleler ve dilin daha küçük birimleri için kullanılmaktadır.” şeklinde belirterek çeviri stratejilerini şu şekilde sıralamıştır: 
1. Aktarım (Transference): Kaynak dildeki bir sözcük, erek dile özgün yazılış şekli ya da okunuşu korunarak transkript ile aktarılır.

2. Yerlileştirme (Naturalization): Bu süreçte kaynak dildeki bir sözcük erek dilde doğal bir morfolojik yapıyla aktarılır.

3. Kültürel eşdeğerlik (Cultural Equivalent): Kültürel ögeleri çevirirken en yaygın kullanılan yöntemdir. Kaynak dildeki bir kültürel kelimenin erek dildeki yakın bir kültürel eşdeğerliğiyle karşılanması sürecidir.

4. İşlevsel eşdeğerlik (Functional Equivalent): Kaynak metindeki kültürel ögelerin kaynak dile özgü olmaktan çıkarılıp objektif bir eşdeğerlikle karşılanmasıyla gerçekleşir.

5. Betimleyici eşdeğerlik (Descriptive Equivalent): Kaynak dildeki bir kültürel ögenin erek dilde birkaç kelime ile açıllanmasıdır.

6. Çok bileşenli tahlil (Componential Analysis): Kaynak dildeki bir kelimenin anlamları tahlil edilip benzerlik ve farklılık değerlendirilerek yaygın anlamı ifade eden bir sözcükle çevirisi yapılır. Birkaç farklı anlamı ifade eden aynı sözcüklerin, erek dilde karşılığının olmaması nedeniyle karşlanamayan anlam için bileşen eklenir.

7. Eş anlamlılık (Synonymy): Kaynak dildeki kelimenin erek dilde eş anlamlı ya da yakın anlamlı bir eşdeğerliğiyle karşılanmasıdır.

8. Öykünme/ alıntılama (Through- translation / Calgue / Loan Translation): Bu yöntem, kaynak metindeki özel isimlerin, birleşik isimlerin, kurum ve kuruluş isimlerinin birebir çevrilmesiyle yapılır.

9. Yer değiştirme (Shifts/ Transposition): Kaynak dilde bir sözcüğün erek dilde karşılığının bulunmadığı durumlarda dil bilgisel düzeyde değissiklikler yapılmasıdır.

10. Düzenleme (Modulation): Kaynak metindeki bir ifadenin erek dilde anlaşllmaz ya da uygunsuz olması durumunda düzenlenerek yeniden aktarılmasıdır.

11. Makul standart çeviri yapma (Recognized Translation): Kaynak dildeki kurum kuruluş isimlerinin erek dilde karşılığının bulunmaması durumunda erek okurun anlayabileceği bir şekilde kabul gören, yaygın anlamıyla ifade edilmesidir.

12. Ödünleme/ telafi (Compensation): Kaynak metinde geçen bir kelimenin erek dilde cümlede gizlenmesi durumunda, cümlenin farklı bölümünde bunun telafi edilmesidir.

13. Redaksiyon ve genişletme (Reduction and Expansion): Kaynak metinde zayıf olan bir ifadenin güçlendirilerek erek dile aktarılmasıyla gerçekleşir.

14. Açımlama (Paraphrase): Genellikle dil ve üslup bakımından zayıf kalan metinlerin çevirisinde açıklama eklenerek çevirinin yapılmasıdır. 
15. Çift süreç kullanma (Couplets): Çeviri yapılırken bir ifadede birkaç stratejinin birlikte kullanılmasidır.

16. Notlar, eklemeler, açıklamalar (Notes, Additions, Glosses): Çeviri yapılırken notlar, eklemeler, açıklamalar eklenerek sözcük açıklanır. Açılamalar cümle içerisinde olabileceği gibi dipnot şeklinde ya da sözlük şeklinde de olabilir.

17. Çıkarma (Deletion): Kaynak metindeki bir ögenin çevirmence erek metinden çıarılmasıdır (Newmark, 2010: 81-93).

\section{Venuti'nin çeviri stratejileri: Yerlileştirme ve yabancılaştırma}

Çeviri bilim alanında öne çıan isimlerden Lawrence Venuti (1995), “The Translator's Invisibility- A History of Translation" adlı eserinde Anglo-Amerikan kültüründe çeviri ve çevirmen arasındaki ilişkiyi "görünebilirlik"/"görünmezlik" ("visibility"/ "invisibility") kavramları ile açıklamıştır. Çevirmenlerin, erek okurların beklentileri doğrultusunda, anlaşılır ve akıcı erek metinler oluşturma yönündeki çeviri stratejileri, erek okurların bu metinlerin kendi kültürlerinden oluştuğunu düşünmelerine sebep olabilecek ve çevirmen görünmezliği söz konusu olacaktır. Bu bağlamda Venuti’nin "yerlileştirme" ("domestication") ve "yabancılaştırma" (foreignization") stratejileri bu görünmezlik ile ilişkilendirilir. Yerlileştirme, çevrilen dilin kültürel özelliklerine göre yapılır. Kaynak metin anlaşılmazlığı en aza indirgenerek erek okurlar tarafından kolaylıkla anlaşılması sağlanır. Yazarı okura yaklaştıran bir durumdur. "Çevirinin amacı kültürel bir ötekinin aynı, fark edilebilir, hatta alışılmış olarak akla getirilmesidir; bu amaç her zaman yabancı metnin tamamen yerlileştirilmeye maruz kalmasına" neden olur (Venuti, 1995: 18). Çevirmenin bu stratejiyi tercih etmesinin farklı nedenleri olabilir. Çevirmen yaşadığı dönemin siyasi ve kültürel özelliklerine göre yerlileştirmeyi seçmiş olabilir (Venuti, 1995: 240241).

Bu stratejide farklı gelen kültürel ögeler çevrilirken, bu ögeleri çıkarma, değiştirme, kendi kültürüne uyarlama gibi çeviri faaliyetleri uygulanabilir. Diğer taraftan yabancılaştırma, okuru yazara götüren, erek okurların metinde farklılıklarla karşılaştı̆̆ı, sorguladığı, şaşırdığı bir stratejidir (Gürçağlar, 2011: 146). Bu stratejide çevirmen, dipnot kullanma, açılama yaparak çevirme, tırnak işareti veya italik yazım biçimiyle farkı vurgulama, sözcüğü sözcüğüne çevirme gibi uygulamalara başvurabilmektedir.

\section{el-Tantûriyye romanındaki kültürel ögelerin çevirisi}

el- Tantûriyye romanındaki kültürel ögelerin çevirisi Newmark'ın sınıflandırması doğrultusunda "Kişisel Yaşam” ana başlı̆̆ındaki- "yiyecekler, kıyafetler, ev eşyaları"- kültürel ögeler örneklerle birlikte analiz edilecektir.

\begin{tabular}{|l|l|}
\hline \multirow{2}{*}{ Radvâ Âşûr } & Kaynak Metin / el- Tantûriyye \\
\cline { 2 - 2 } & \multicolumn{1}{|c|}{ (s.96). في يوم واحد ملوخية، ووظيفة ومنحة. طبعا الملوخية أهم. } \\
\hline $\begin{array}{l}\text { Ceve. N. Zehra } \\
\text { Kalkancı }\end{array}$ & $\begin{array}{l}\text { "Aynı gün hem muluhiyye, hem iş hem de burs var! Tabii ki muluhiyye daha önemli.” } \\
\text { (s.89) }\end{array}$ \\
\hline $\begin{array}{l}\text { Newmark'mn } \\
\text { Stratejileri }\end{array}$ & Aktarma \\
\hline
\end{tabular}




\begin{tabular}{|l|l|}
\hline $\begin{array}{l}\text { Venuti'nin } \\
\text { Stratejileri }\end{array}$ & Yabancllaştırma \\
\hline
\end{tabular}

ÖRNEK 1

Yiyecekler kapsamında ele alacağımız الملوخية sözcüğünün erek kültürde karşıllğı bulunmadığından aktarım yoluyla çevrilmiştir. Erek metinde okuyucu tarafindan anlaşılması zor olacağından dipnot kullanılarak açıklama yoluna gidilmiştir. Kaynak kültür korunarak, okurun hedef kültüre yönlendirilmesi sağlanmış ve yabancılaştırma stratejisine başvurulmuştur.

\begin{tabular}{|c|c|}
\hline \multirow[t]{2}{*}{ Radvâ Âşûr } & Kaynak Metin / el- Tantûriyye \\
\hline & الغداء! (s.192) ألأمين الله برحمه، زار نابلس في الزمانات. قال كنافة أهل نابلس ليس لها مثيل، ولكنهم يقدمونها قبل \\
\hline \multirow{2}{*}{$\begin{array}{l}\text { Çev. N. Zehra } \\
\text { Kalkanci }\end{array}$} & Erek Metin / Tantûralı Kadın \\
\hline & $\begin{array}{l}\text { Ebu Emin amcan- Allah rahmet eylesin- vakti zamanında Nablus'a gitmişti. Nablus } \\
\text { künefesi üstüne yok, ama ne yazık ki yemekten önce ikram ediyorlar, diye anlatırdı. } \\
\text { (s.173) }\end{array}$ \\
\hline $\begin{array}{l}\text { Newmark'in } \\
\text { Stratejileri }\end{array}$ & Kültürel Eşdeğerlik \\
\hline $\begin{array}{l}\text { Venuti'nin } \\
\text { Stratejileri }\end{array}$ & Yerlileştirme \\
\hline
\end{tabular}

ÖRNEK 2

Kaynak metindeki كنافة kelimesinin erek kültürde tam karşllğ̆ künefedir ve bunun erek kültürde bulunması, erek okuyucu tarafından kolayca anlaşılmasına imkân vererek yerlileştirme stratejisi kullanılmıştır.

\begin{tabular}{|l|l|}
\hline \multirow{2}{*}{ Radvâ Âşûr } & Kaynak Metin / el- Tantûriyye \\
\cline { 2 - 2 } & \multicolumn{1}{|c|}{ (s.221) الت وجدت بعض الطحين قلت أخبز. أوشك أن أنتهي على أي حال } \\
\hline $\begin{array}{l}\text { Çev. N. Zehra } \\
\text { Kalkancı }\end{array}$ & Erek Metin / Tantûralı Kadın \\
\cline { 2 - 2 } & "Biraz tahin buldum, hamur yoğurayım dedim. Zaten bitirmek üzereyim.” (s.200) \\
\hline $\begin{array}{l}\text { Newmark’in } \\
\text { Stratejileri }\end{array}$ & Aktarma \\
\hline $\begin{array}{l}\text { Venuti'nin } \\
\text { Stratejileri }\end{array}$ & Yabanclaştırma \\
\hline
\end{tabular}

ÖRNEK 3

Kaynak metinde geçen الطحين sözcüğ̈̈, okunuşu korunarak aktarım yoluyla erek metne aktarılmıştır. sözcüğü Türkçede un anlamına gelmektedir. Fakat burada kaynak metinde geçen anlam karşılanmadığından erek okur tarafından anlaşılmazlığa neden olabilmektedir. Yabancılaştırma stratejisine başvurulmuştur. 


\begin{tabular}{|c|c|}
\hline \multirow[t]{2}{*}{ Radvâ Âşûr } & Kaynak Metin / el- Tantûriyye \\
\hline & أقول: فاطهة تحبن النيتن زجاجتين كبيرتين. (s.412) \\
\hline \multirow{2}{*}{$\begin{array}{l}\text { Çev. N. Zehra } \\
\text { Kalkancı }\end{array}$} & Erek Metin / Tantûralı Kadın \\
\hline & $\begin{array}{l}\text { "Fatıma mekdus sever" diyorum. Küçük siyah patlıcan alıp ceviz ve acı biber sosuyla } \\
\text { dolduruyorum. Zeytinyağı ve limonla iki büyük kavanoza basıp kuruyorum. (s.359) }\end{array}$ \\
\hline $\begin{array}{l}\text { Newmark'un } \\
\text { Stratejileri }\end{array}$ & Aktarma \\
\hline $\begin{array}{l}\text { Venuti'nin } \\
\text { Stratejileri }\end{array}$ & Yabancılaştırma \\
\hline
\end{tabular}

ÖRNEK 4

Kaynak metinde yer alan المكدوس sözcüğünün erek dilde bir karşıllğı̆ olmadığından anlamı ve okunuşu korunarak aktarım yoluyla erek metne aktarılmış ve dipnot kullanılarak erek okura kaynak kültür hakkında bilgi verilmiştir. Kaynak kültür korunarak yabancılaştırma stratejisine başvurulmuştur.

\begin{tabular}{|c|c|}
\hline \multirow[t]{2}{*}{ Radvâ Âşûr } & Kaynak Metin / el- Tantûriyye \\
\hline & و الر اديو مثل المضافة في تللك الأيام، مخصوص لمعرفة ما يجري من وقائع و أخبار. (s.34) \\
\hline \multirow{2}{*}{$\begin{array}{l}\text { Çev. N. Zehra } \\
\text { Kalkancı }\end{array}$} & Erek Metin / Tantûralı Kadın \\
\hline & $\begin{array}{l}\text { Radyo ise o günlerde köyün misafirhanesi gibi gerçekleşen olayları ve haberleri } \\
\text { öğrenebilmeye mahsustu. (s.31) }\end{array}$ \\
\hline $\begin{array}{l}\text { Newmark'in } \\
\text { Stratejileri }\end{array}$ & Kültürel Eşdeğerlik \\
\hline $\begin{array}{l}\text { Venuti'nin } \\
\text { Stratejileri }\end{array}$ & Yerlileştirme \\
\hline
\end{tabular}

ÖRNEK 5

Ev eşyaları kapsamında ele alacağımız الراديو sözcüğünün erek dildeki karşıllğ̆1 radyodur, iki dilde de anlam ortaktır. Erek okur tarafından kolayca kabul görmektedir, yerlileştirme stratejisi kullanılmıştır.

\begin{tabular}{|c|c|}
\hline \multirow[t]{2}{*}{ Radvâ Âşûr } & Kaynak Metin / el- Tantûriyye \\
\hline & السلاح. (s.36) (للاجلاح صارت كثربة ماء، ضرورية للبقاء. أصبح الحديث مشاعا حتى بين نساء القرية عن شراء \\
\hline \multirow{2}{*}{$\begin{array}{l}\text { Çev. N. Zehra } \\
\text { Kalkanci }\end{array}$} & Erek Metin / Tantûralı Kadın \\
\hline & $\begin{array}{l}\text { Silaha olan ihtiyaç, su içmek gibi hayatta kalabilmek için şarttı. Köyün kadınları } \\
\text { arasında bile silah satın alma sohbetleri dönmeye başlamıştı. (s.33) (s.36) }\end{array}$ \\
\hline $\begin{array}{l}\text { Newmark'in } \\
\text { Stratejileri }\end{array}$ & Kültürel Eşdeğerlik \\
\hline $\begin{array}{l}\text { Venuti'nin } \\
\text { Stratejileri }\end{array}$ & Yerlileştirme \\
\hline
\end{tabular}

ÖRNEK 6 
السلاح sözcüğünün birebir karşılığı silah sözcügüüür. Erek kültürde de aynı anlamda kullanıldığından erek okurca anlaşılması kolaydır, istenilene uygun bir çeviridir ve yerlileştirme stratejisine başvurulmuştur.

\begin{tabular}{|c|c|}
\hline \multirow[t]{2}{*}{ Radvâ Âşûr } & Kaynak Metin / el- Tantûriyye \\
\hline & أمي قامت تبحث عن بخور لأنها أيقتت أن عينا أصابتهما. (s.44) \\
\hline \multirow{2}{*}{$\begin{array}{l}\text { Çev. N. Zehra } \\
\text { Kalkancı }\end{array}$} & Erek Metin / Tantûralı Kadın \\
\hline & $\begin{array}{l}\text { Annem kalkmış yakmak için tütsü arıyordu çünkü ikisine de nazar değdiğinden } \\
\text { emindi. (s.41) }\end{array}$ \\
\hline $\begin{array}{l}\text { Newmark'in } \\
\text { Stratejileri }\end{array}$ & İşlevsel Eşdeğerlik \\
\hline $\begin{array}{l}\text { Venuti'nin } \\
\text { Stratejileri }\end{array}$ & Yerlileştirme \\
\hline
\end{tabular}

ÖRNEK 7

Kaynak metinde بخور sözcüğünün nazarı aldığına değinilmiştir. Erek kültürde de tütsü sözcüğünün nazara iyi geleceği inancı vardır. Çevirmen, işlevsel eşdeğerlik stratejisi ile erek metne aktarmıştır. Yerlileştirme stratejisi ile erek okurlarca anlaşılması kolay olacaktır.

\begin{tabular}{|l|l|}
\hline \multirow{2}{*}{ Radvâ Âşûr } & Kaynak Metin / el- Tantûriyye \\
\cline { 2 - 2 } & \multicolumn{1}{|c|}{ (s.92) مثل أمي سييقى المفتاح معلقا في عنقي. في الصحو و المنام. لا أخلعه حتى في الحمام. $\begin{array}{l}\text { Crev. N. Zehra } \\
\text { Kalkancı }\end{array}$} \\
\cline { 2 - 2 } & $\begin{array}{l}\text { Anneminki gibi, anahtar benim de boynumda asılı kalacak. Uyanıkken ve uyurken. } \\
\text { Banyodayken bile çıkarmayacaktım. (s.85) }\end{array}$ \\
\hline $\begin{array}{l}\text { Newmark'in } \\
\text { Stratejileri }\end{array}$ & Kültürel Eşdeğerlik \\
\hline $\begin{array}{l}\text { Venuti'nin } \\
\text { Stratejileri }\end{array}$ & Yerlileştirme \\
\hline
\end{tabular}

ÖRNEK 8

Ev eşyaları kapsamında inceleyeceğimiz المفتاح, sözlük anlamı ile kullanılarak kültürel eşdeğerlik stratejisine gidilmiştir. Kaynak kültürdeki anahtarın Filistinli kadınlar açısından ne ifade ettiği belirtilmiştir, yerlileştirme stratejisine başvurulmuştur.

\begin{tabular}{|c|c|}
\hline \multirow[t]{2}{*}{ Radvâ Âşûr } & Kaynak Metin / el- Tantûriyye \\
\hline & ويمسك بعصاه. (s.118) مئرب قهوته بسر عة في الصباح ثم برتدي قمبازه والجاكيت و يضبط الحطة و العقال، \\
\hline \multirow{2}{*}{$\begin{array}{l}\text { Çev. N. Zehra } \\
\text { Kalkancı }\end{array}$} & Erek Metin / Tantûralı Kadın \\
\hline & $\begin{array}{l}\text { Ebu Emin amcam, sabah erkenden kahvesini hızla içer sonra entarisini ve ceketini } \\
\text { giyer; kefiyesiyle çemberini takıp bastonunu eline alırdı. (s.108) }\end{array}$ \\
\hline $\begin{array}{l}\text { Newmark'm } \\
\text { Stratejileri }\end{array}$ & Öykünme/ Alıntılama \\
\hline
\end{tabular}




\begin{tabular}{|l|l|}
\hline $\begin{array}{l}\text { Venuti'nin } \\
\text { Stratejileri }\end{array}$ & Yabancllaştırma \\
\hline
\end{tabular}

ÖRNEK 9

Kiyafetler kapsamında inceleyeceğimiz kaynak metinde geçen العقال ,الحطة ,الجاكيت ,قمباز sözcükleri erek metne birebir çevrilmiştir. قبباز erkeklerin giydiği uzun elbise, entari anlamındadır. الحطبة erkeklerin başları ve boyunlarına doladıkları şaldır ve kefiye olarak çevrilmiştir, العقال sözcüğ̈̈ ise kefiyenin üzerine takılan çember şeklinde siyah kalıp iptir. Ceket haricindeki kelimeler erek kültürde kullanılmadığından erek okurca anlaşılması güç olabilmektedir. Erek okur yeni bir kültürle karşı karşıyadır. Yabancılaştırma stratejisi kullanılmıştır.

\begin{tabular}{|c|c|}
\hline \multirow[t]{2}{*}{ Radvâ Âşûr } & Kaynak Metin / el- Tantûriyye \\
\hline & و و عنل يمينه الصادق يرندي ما يليق بموظف شاب في البنك العربي: بدلة وطربوش، و إلى يساره حسن في \\
\hline \multirow{2}{*}{$\begin{array}{l}\text { Çev. N. Zehra } \\
\text { Kalkancı }\end{array}$} & Erek Metin / Tantûralı Kadın \\
\hline & $\begin{array}{l}\text { Sağında Sadık var, Arap Bankasında çalışan memurlara yakışır biçimde giyinmiş: } \\
\text { Takım elbise ve fes. Solunda pantolon ve gömleğiyle Hasan. (s.116) }\end{array}$ \\
\hline $\begin{array}{l}\text { Newmark'in } \\
\text { Stratejileri }\end{array}$ & İşlevsel Eşdeğerlik \\
\hline $\begin{array}{l}\text { Venuti'nin } \\
\text { Stratejileri }\end{array}$ & Yerlileştirme \\
\hline
\end{tabular}

ÖRNEK 10

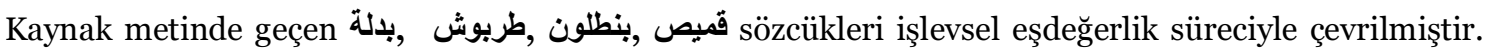
Kelimeler birebir anlamlarıyla çevrilerek erek metne aktarılmıştır. Okuyucu tarafından anlaşılması kolay olacaktır.

\begin{tabular}{|l|l|}
\hline \multirow{2}{*}{ Radvâ Âşûr } & Kaynak Metin / el- Tantûriyye \\
\cline { 2 - 2 } & \\
\hline $\begin{array}{l}\text { Çev. N. Zehra } \\
\text { Kalkancı }\end{array}$ & Erek Metin / Tantûralı Kadın \\
\cline { 2 - 2 } & "Lübnan'daki arkadaşlarımın çocukları için kazak örüyorum" diyorum. (s.250) \\
\hline $\begin{array}{l}\text { Newmark'ın } \\
\text { Stratejileri }\end{array}$ & Yer Değiştirme \\
\hline $\begin{array}{l}\text { Venuti'nin } \\
\text { Stratejileri }\end{array}$ & Yerlileştirme \\
\hline
\end{tabular}

ÖRNEK 11

kنزات kelimesinin erek dildeki karşllığı kazaklardır. Çevirmen yer değiştirme stratejisine başvurarak kazak olarak çevirmeyi tercih etmiş ve kaynak metindeki çoğul ifade erek metne tekil olarak aktarılmıştır. Dilbilgisel düzeyde değişikliğe gidilerek erek dildeki ifadenin bağlama uygun olması sağlanmıştır. 
842 / RumeliDE Journal of Language and Literature Studies 2021.25 (December)

An analysis on the translation of cultur elements in Radva Asur's “The Woman From Tantura" / A. Aldyab; T. Kettaneh (pp. 831843)

\begin{tabular}{|c|c|}
\hline \multirow[t]{2}{*}{ Radvâ Âşûr } & Kaynak Metin / el- Tantûriyye \\
\hline & هذا التطريز سهرت عليه الليالي. اسمه "فلاحي". هذا ثوب فلسطيني فلاحي. (s.322) \\
\hline \multirow{2}{*}{$\begin{array}{l}\text { Çev. N. Zehra } \\
\text { Kalkancı }\end{array}$} & Erek Metin / Tantûrah Kadın \\
\hline & $\begin{array}{l}\text { "Bu nakış var ya onu yapmak için gecelerce uyanık kaldım! Adı 'fellahi' bu Filistin } \\
\text { köylü kıyafeti." (s.286) }\end{array}$ \\
\hline $\begin{array}{l}\text { Newmark'in } \\
\text { Stratejileri }\end{array}$ & Aktarım \\
\hline $\begin{array}{l}\text { Venuti'nin } \\
\text { Stratejileri }\end{array}$ & Yabancılaştırma \\
\hline
\end{tabular}

ÖRNEK 12

Fellahi (فلاحي) sözcüğ̈̈ kaynak metindeki okunuşu korunarak erek metne aktarım yoluyla çevrilmiştir. Filistinli kadınların özel günlerde giydikleri kanaviçe nakışıla işlenerek dikilen bir elbisedir. Cümlenin bağlamından kelimenin anlamı okur tarafından anlaşılacaktır. Kaynak kültür korunarak yabancılaştırma stratejisi kullanılmıştır.

\section{Sonuç}

Arap Edebiyatı ünlü yazarlarından Radvâ Âşûr'un el- Tantûriyye adlı eseri Peter Newmark'ın kültürel ögeler sınıflandırmasına göre ele alınmıştır. Ayrıca, Newmark’ın çeviri stratejileri ve Venuti'nin yerlileştirme ve yabancılaştırma stratejileri kapsamında incelenmiştir. Yapılan incelemeler doğrultusunda kültürel ögelerin çevirisinde, kaynak dil ve kültüre hakimiyetin yanı sıra bunu erek dile makul ve en anlaşılır biçimde aktarabilmek için çevirmen yeterliliği oldukça önemli ve gereklidir. Kaynak kültüre uzak olarak yapılan çeviri, çeviri kayıplarına ve kaynak kültürün yanlış tanınması sonucu kültür kayıplarına neden olabilmektedir. Çevirmen için önemli olan kültürel ögeleri çözümleme ve anlayıp yorumlayarak aktarmaktır. Çalışma bulgularında, erek okura yabancı gelecek ve onları yeni bir kültüre açabilecek "yabancılık" gözler önüne serilerek yer yer dipnotlara da yer verilerek yabancllaştırma stratejisine başvurulmuştur. Farklı kültürlerin tanışarak, dil ve kültürlerin zenginleşmesi için güzel bir fırsattır. Tahsin Yücel’in "Anlatı Çevirisinde değindiği gibi "Bir kaynak metni kendi dilimize uydurmak değil de çevirmek istiyorsak, aykırllıktan çekinmemek gerekir” (Yücel, 2008:103).

Diğer yandan yer yer kaynak ve erek metinde bulunan ve aynı kavramlara işaret eden kültürel ögelerin çevirisinde metin anlaşılırlı̆̆ sağlanarak, erek dil ve kültürü de ön planda tutularak "yerlileştirme" stratejisine gidilmiştir. Sonuç olarak kültürel ögeler, ait olduğu kültüre dair erek okuyucu kitlesine bambaşka dünyanın kapılarını açarak kültürel ögelerin anlaşılıp tanınmasına olanak sağlar. Buradaki en büyük görev çevirmene düşmektedir. Tercih ettiği yöntem ve stratejilerle çevirinin kültürler arası etkileşimi arttırmasına katkısı büyük olacaktır.

\section{Kaynakça}

Akalın, Ş. H. [v.d). (2011). Türkçe Sözlük. Ankara: Türk Dil Kurumu.

Aşur, R. (2010). el- Tanturiyye. Kahira: eş- Şuruk.

Baykan, A. (2005). Sosyal- Kültürel Faktörlerin Çevirideki Rolü. Selçuk Üniversitesi Sosyal Bilimler Enstitüsü Dergisi, Sayı:14, 177- 197.

Bölükbaşı, M. (2021). Araplar'da çeviri biliminin ortaya çıkışı ve Câhiz’in konu hakkındaki düşünceleri. RumeliDE Dil ve Edebiyat Araştırmaları Dergisi, (23), 720-730. 
Bölükbaşı, M. (2021). Arapçadan Türkçeye Yapılan Çevirilerde Kültür Aktarımı. (Ed.) Kara, Ö. T. Erol, S. Güncel Alan Eğitimi Araştırmaları III. Ankara: Akademisyen Kitabevi.

Çamdereli, M. (1995). "Uluslararası İletişimde Dil ve Dil Aktarımı" Uluslararası İletişim içinde (haz.) Öngören, G. İstanbul: Der Yayınları.

Eagleton, T. (2011). Kültür Yorumları. (Çev.) Ö. Çelik, İstanbul: Ayrıntı Yayınları.

Göçer, A. (2012). Dil- Kültür İlişkisi ve Etkileşimi Üzerine. Türk Dili, Sayı:729, 50-57.

Gürçağlar, Ş. T. (2011). Çevirinin ABC'si. İstanbul: Say Yayınları.

Kalkancı, R. Â. (2019). Tantûralı Kadın. İstanbul: Ketebe Yayınları.

Kaplan, M. (2020). Kültür ve Dil. İstanbul: Dergâh Yayınları.

Mutçalı, S. (1995). Arapça- Türkçe Sözlük. İstanbul: Dağarcık Yayınları.

Newmark, P. (1981). Approaches to Translation. Londra: Pergamon Press.

Newmark, P. (1988). A Textbook of Translation. UK: Prentice Hall.

Suçin, M. H. (2013). Öteki Dilde Var Olmak- Arapça Çeviride Eşdeğerlik. İstanbul: Say Yayınları.

Taş, S. (2017). Kültürel Unsurların Çevirisi ve Çeviri Stratejileri. Humanitas Uluslararası Sosyal Bilimler Dergisi, 5(10), S.1- 14.

Toven, M. B. (1924). Yeni Türkçe Lügat. Ankara: Türk Dil Kurumu Yayınları.

Venuti, L. (1998). Translator's Invisibility: A History of Translation. London and Newyork: Routledge.

Yücel, T. (2008). "Anlatı Çevirisi". Çeviri Seçkisi I: Çeviriyi Düşünenler (haz.) Rifat,M. İstanbul: Sel Yayıncilik. 